\title{
Reciprocal co-expression of Fas and Fas ligand in human cholangiocarcinoma
}

\author{
GEORGE PAN ${ }^{1}$, EUN-YOUNG AHN ${ }^{1}$, YABING CHEN ${ }^{1}$, GONG FENG ${ }^{1}$, \\ VISHNU REDDY $^{1}$, NIRAG C. JHALA ${ }^{1}$ and JAY M. McDONALD ${ }^{1,2}$ \\ ${ }^{1}$ Department of Pathology, University of Alabama at Birmingham, Birmingham, AL 35294; \\ ${ }^{2}$ Veterans Administration Medical Center, Birmingham, AL 35233, USA
}

Received March 6, 2007; Accepted April 25, 2007

\begin{abstract}
We have previously characterized the role of Fas in tumorigenesis using two cholangiocarcinoma cell lines expressing high $\left(\mathrm{Fas}^{\mathrm{H}}\right)$ and low $\left(\mathrm{Fas}^{\mathrm{L}}\right)$ levels of Fas. Here we further characterize Fas ligand (FasL) expression and function in these two cell lines. The Fas ${ }^{\mathrm{L}}$ cells expressed a high level of FasL, whereas the Fas ${ }^{\mathrm{H}}$ cells expressed a low level of FasL showing reciprocal expression of Fas and FasL in tumor cells. FasL released from the Fas ${ }^{\mathrm{L}}$ cells is capable of inducing apoptosis of lymphocytes, which is blocked by neutralizing Fas antibody. To study the underlying mechanism for the reciprocal expression of Fas and FasL, we examined the activities of both the Fas and FasL promoters. The activity of the Fas promoter is suppressed and the activity of the FasL promoter is stimulated in the $\mathrm{Fas}^{\mathrm{L}}$ cells compared to the $\mathrm{Fas}^{\mathrm{H}}$ cells. The inverse activities of Fas and FasL promoter in tumor cells are regulated by $\mathrm{NF}-\kappa \mathrm{B}$, which inhibits Fas expression and increases FasL expression through binding to their respective promoters. The inverse expression of Fas and FasL in tumor cells is partially reversed by an NF- $\mathrm{NB}$ inhibitor. In conclusion, human cholangiocarcinoma cells reciprocally co-express functional Fas and FasL, which are the result of the activities of the Fas and FasL promoters being regulated by NF- $\kappa \mathrm{B}$. These findings provide a potential unifying molecular mechanism for modulating tumorigenesis via Fas/FasL expression.
\end{abstract}

\section{Introduction}

Cholangiocarcinoma represents a challenging primary malignant tumor with no effective medical therapy and a poor prognosis. The etiology of cholangiocarcinoma remains

Correspondence to: Dr Jay M. McDonald, Department of Pathology, University of Alabama at Birmingham, 70119 Street S., LHR 504, Birmingham, AL 35294, USA

E-mail: jmcdonald@path.uab.edu

Key words: Fas/APO-1(CD95), Fas ligand, cholangiocarcinoma, apoptosis, $\mathrm{NF}-\kappa \mathrm{B}$ unknown. In our previous investigations, we have demonstrated that human cholangiocarcinoma cell lines heterogeneously express Fas antigen at the cell surface. We have isolated two subpopulations based on their Fas levels: one with low Fas expression $\left(\mathrm{Fas}^{\mathrm{L}}\right)$ and the other with high Fas expression $\left(\mathrm{Fas}^{\mathrm{H}}\right)(1,2)$. The Fas ${ }^{\mathrm{L}}$ cells, but not $\mathrm{Fas}^{\mathrm{H}}$ cells, are resistant to apoptosis induced by Fas activating antibody and by other apoptotic stimuli (3-5) and are capable of producing tumors when subcutaneously injected into nude mice $(2,5)$. These results suggest that the down-regulation of Fas expression and resistance to Fas-activated apoptosis might play a crucial role in the tumorigenesis of cholangiocarcinoma.

Although decreased Fas expression in tumors is frequently associated with enhanced malignant growth or metastasis $(6,7)$, a decrease in Fas expression alone is unlikely to be entirely responsible for the enhanced neoplastic growth and metastasis (8). Tumor cells must require additional molecular mechanisms to render them resistant to host immune attack (9). Malignant cells have several mechanisms to escape immune surveillance including expression of low levels of target tumor antigens (10). Expression of FasL on tumor cells is also one of the mechanisms by which malignant cells escape the host immune attack. It has been reported that many carcinomas aberrantly express FasL, whereas the parallel normal tissues do not (11-13). Expression of FasL by malignant tumors may counteract the host's anti-tumor immunity and favor tumor growth by killing infiltrating $\mathrm{T}$ lymphocytes through Fas-FasL interaction (14-16). When FasL-positive melanoma cells were injected into mice, tumors developed more rapidly in wild-type mice compared with Fas deficient $l p r$ mutants, suggesting that functional FasL on tumors may be involved in the destruction of immune cells and in maintaining a state of tumor immune privilege (17).

The hypothesis that FasL is important for tumor growth and immune privilege has been challenged $(18,19)$. Tumor cells transfected with the gene encoding FasL induced rapid tumor regression rather than fostering tumor development. However, the level of Fas expression by these transfected tumor cells was not indicated $(14,20,21)$. We hypothesized that simultaneously decreased Fas expression and increased FasL expression in tumor cells are required for tumor growth or metastasis. Reciprocal expression of Fas and FasL in tumors has been observed in previous studies $(22,23)$. However, the underlying mechanisms for their expression have not been 
elucidated. In this study, we found a reciprocal relationship between Fas and FasL levels in the $\mathrm{Fas}^{\mathrm{H}}$ and $\mathrm{Fas}^{\mathrm{L}}$ human cholangiocarcinoma cell lines, which is associated with high levels of NF- $\kappa \mathrm{B}$ transcription factor in the $\mathrm{Fas}^{\mathrm{L}}$ tumor cells. Increased NF- $\mathrm{KB}$ transcription factor simultaneously inhibited Fas and stimulated FasL expression in the Fas ${ }^{\mathrm{L}}$ tumor cells. Our results provided important insight into the underlying molecular mechanism regulating Fas and FasL expression and thus tumorigenesis.

\section{Materials and methods}

Cell culture. Human cholangiocarcinoma cells (SK-ChA-1) were generously provided by Dr A. Knuth (Ludwig Institute for Cancer Research, London, UK) and their growth conditions were described previously $(1,2)$. Cells were subcloned by flow cytometric sorting into two subpopulations, those expressing low amounts of Fas $\left(\mathrm{Fas}^{\mathrm{L}}\right)$ and those expressing high amounts of Fas $\left(\mathrm{Fas}^{\mathrm{H}}\right)$, as previously reported $(1,2)$.

Isolation of RNA and quantitative real-time RT-PCR. Total RNA was isolated with TRIzol reagent (Invitrogen, Palo Alto, CA) according to the manufacturer's protocol. Firststrand cDNA was synthesized by annealing RNA $(1 \mu \mathrm{g})$ with $250 \mathrm{ng}$ of random primers by heating at $70^{\circ} \mathrm{C}$ for $2 \mathrm{~min}$. After denaturing, samples were incubated with reverse transcriptase, $10 \mathrm{mM}$ dithiothreitol, RNasin (Promega, Madison, WI) and $0.5 \mathrm{mM}$ dNTPs in a total volume of $20 \mu \mathrm{l}$ for $1 \mathrm{~h}$ at $42^{\circ} \mathrm{C}$. The reaction mixture was diluted to a final volume of $100 \mu \mathrm{l}$ and heat-inactivated at $95^{\circ} \mathrm{C}$ for $5 \mathrm{~min}$.

Real-time RT-PCR was performed on an ABI GeneAmp 5700 sequence detection system using SYBR-Green labeling primers (Applied Biosystems, Foster City, CA). In the total volume of $25 \mu 1$ reaction mixture, $22.5 \mu 1$ master mix, $2.5 \mu 1$ cDNA (corresponding to $25 \mathrm{ng}$ of total RNA), and $6 \mu \mathrm{M}$ of forward and reverse primers were added. The reaction mixture was heated for $5 \mathrm{~min}$ at $95^{\circ} \mathrm{C}$ and then $40 \mathrm{PCR}$ cycles consisting of $15 \mathrm{sec}$ at $95^{\circ} \mathrm{C}$ and $60 \mathrm{sec}$ at $60^{\circ} \mathrm{C}$ were performed. The product accumulation was monitored by SYBR-Green fluorescence (24). The sequences of primers used for realtime RT-PCR were as follows: GAPDH 5'-GATTCCACCC ATGGGAATT-3' (forward), 5'-GGGTGGTGGAAGATGGT GAT-3' (reverse); Fas 5'-ACTTCGGAGGATTGCTCAACA-3' (forward), 5'-ACTTCGGAGGATTGCTCAACA-3' (reverse); and FasL 5'-AAAGTGGCCGATTTAACAGGC-3' (forward), 5'-GCAACAGACGTAAGAACCAGAGG-3' (reverse). The relative gene expression levels were determined from the standard curve and were calculated using software provided by the manufacturer (Applied Biosystems).

Northern blotting of Fas and FasL. Total mRNA (20 $\mu \mathrm{g} / \mathrm{lane})$ isolated from the cultured $\mathrm{Fas}^{\mathrm{H}}$ and $\mathrm{Fas}^{\mathrm{L}}$ cells was denatured and electrophoretically separated on $2.2 \%$ agarose gels containing $6 \%$ formaldehyde. The gels were then transferred to nitrocellulose membranes and fixed by UV light crosslinking. Membranes were prehybridized in QuikHyb hybridization buffer (Stratagene, La Jolla, CA) at $65^{\circ} \mathrm{C}$ for $1 \mathrm{~h}$ and then hybridization was continued in QuikHyb hybridization buffer containing $8 \times 10^{5} \mathrm{cpm} / \mathrm{ml}$ of $\left[\gamma^{-32} \mathrm{P}\right]$-labeled Fas or FasL cDNA probes for a further $1 \mathrm{~h}$. The Fas and FasL probes were generated with a T7 sequence using $\left[\gamma_{-}{ }^{32} \mathrm{P}\right] \mathrm{UTP}$ and a T7 RNA polymerase. The labeled RNA transcripts were purified by G-25 Sephadex chromatography (Boehringer Mannheim, Indianapolis, IN). Membranes were washed 3 times for $20 \mathrm{~min}$ at $65^{\circ} \mathrm{C}$ in $1 \mathrm{X} \mathrm{SSC}$ and then exposed to film for $16 \mathrm{~h}$.

Western blotting of Fas and FasL. Western blotting was performed using lysates (20 $\mu \mathrm{g}$ protein) from the $\mathrm{Fas}^{\mathrm{H}}$ and Fas $^{\mathrm{L}}$ cells as described previously (3-5). Primary antibodies were rabbit anti-human Fas (diluted 1: 200, clone C-20) or mouse anti-human FasL (diluted 1:250, clone N-20; Santa Cruz Biotechnology, Santa Cruz, CA). After washing, membranes were incubated with a goat anti-rabbit (or goat anti-mouse) IgG-antibody conjugated to horseradish peroxidase at a 1:5,000 dilution as the second antibody. Anti-GAPDH antibody was used for loading control.

Chromium release assay. The $\mathrm{Fas}^{\mathrm{H}}$ and $\mathrm{Fas}^{\mathrm{L}}$ cells were grown to $80 \%$ confluence. These effector cells (E) were then resuspended in RPMI-1640 complete medium at $1 \times 10^{7} / \mathrm{ml}$. Fasbearing sensitive A20 $\left(2 \times 10^{6}\right)$ target cells (T) were suspended in $0.5 \mathrm{ml}$ RPMI-1640 complete medium and labeled with $25 \mu \mathrm{l}$ ${ }^{51} \mathrm{Cr}(30 \mu \mathrm{Ci})$ at $37^{\circ} \mathrm{C}$ for $1 \mathrm{~h}$. After washing twice with $50 \mathrm{ml}$ complete medium, labeled A20 cells were resuspended at a concentration of $1 \times 10^{6} / \mathrm{ml}$ and then seeded into a 96-well plate $\left(1 \times 10^{5}\right.$ cells $/ 0.1 \mathrm{ml} /$ well). The ${ }^{51} \mathrm{Cr}$-labeled A20 cells (T) were incubated with $0.1 \mathrm{ml} \mathrm{Fas}{ }^{\mathrm{H}}$ or $\mathrm{Fas}^{\mathrm{L}}$ cells $(\mathrm{E})$ at $\mathrm{E} / \mathrm{T}$ ratios of $3: 1,6: 1,12: 1$ and $24: 1$ overnight. The plate was centrifuged and $100 \mu 1$ supernatant was removed to determine radioactivity by a liquid scintillation counter. The maximum and minimum radioactivity were determined by counting ${ }^{51} \mathrm{Cr}$ in the supernatant of ${ }^{51} \mathrm{Cr}-\mathrm{A} 20$ cells alone in the presence (maximum) and absence (minimum) of $0.1 \%$ SDS. The specific toxicity was calculated as follows: Specific toxicity $=[($ sample CPM $)$ - (minimum CMP)]/[(maximum CPM) - (minimum CPM)] x 100 .

Isolation of FasL from cell culture supernatants. FasL from tumor cell supernatants was isolated as described previously $(9,25,26)$. Briefly, cell culture supernatants collected from the $\mathrm{Fas}^{\mathrm{H}}$ and $\mathrm{Fas}^{\mathrm{L}}$ tumor cells were centrifuged twice at $200 \mathrm{x} \mathrm{g}$ for $20 \mathrm{~min}$ at $4^{\circ} \mathrm{C}$ followed by ultracentrifuging at $47,000 \mathrm{x} \mathrm{g}$ at $4^{\circ} \mathrm{C}$ for $3 \mathrm{~h}$ (Beckman, T50). The microvesicle pellet was washed with PBS and then treated with or without $1 \%$ Triton $\mathrm{X} 100$ at $4^{\circ} \mathrm{C}$ for $30 \mathrm{~min}$. The microvesicle supernatant was collected and stored at $-80^{\circ} \mathrm{C}$ after centrifuging at $23,000 \times \mathrm{g}$ at $4^{\circ} \mathrm{C}$ for $1 \mathrm{~h}$.

Assessment of released FasL bioactivity. The function of FasL released from tumor cells was determined as described previously (26). Jurkat cells were cultured with the indicated volumes of the prepared microvesicle supernatants overnight. The medium and Fas activating antibody $(50 \mathrm{ng} / \mathrm{ml})$ were used as a negative and a positive control. After incubation, apoptosis was determined by an Annexin V assay as per the manufacturer's instructions.

Electrophoretic mobility shift analysis (EMSA). Nuclear extracts were prepared as described previously (27). The double-stranded oligonucleotides containing the consensus 
A
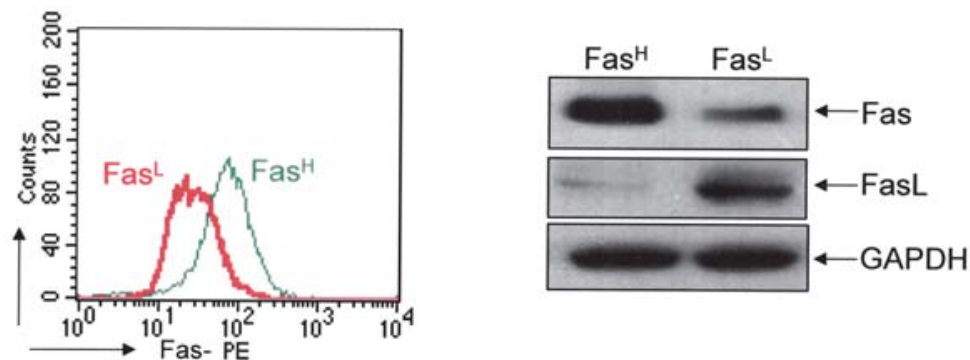

B

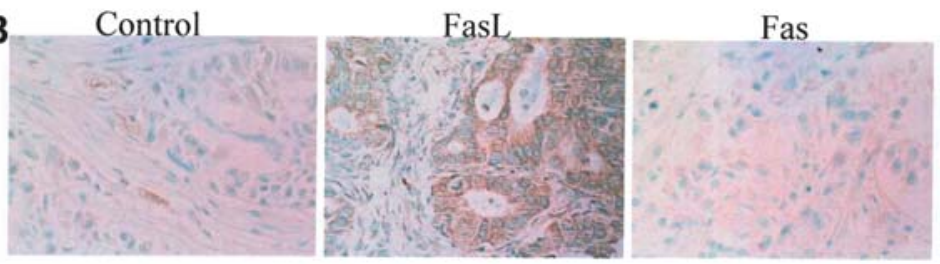

FasL

Fas

C

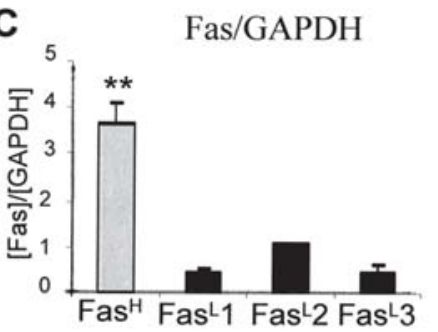

FasL/GAPDH

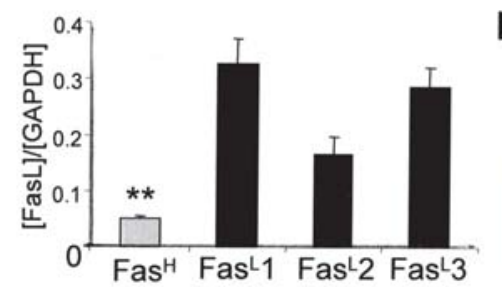

D

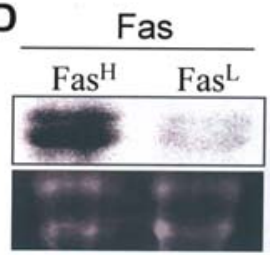

FasL

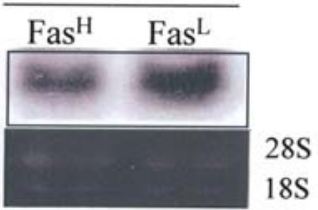

Figure 1. Fas ${ }^{\mathrm{H}}$ and $\mathrm{Fas}^{\mathrm{L}}$ human cholangiocarcinoma cells inversely co-express Fas and FasL proteins. (A) Cultured human cholangiocarcinoma cells (SKChA-1) were stained for Fas using a PE-conjugated mouse anti-Fas antibody. Cells were sorted and cloned into the Fas ${ }^{\mathrm{H}}$ clones with a high expression level of Fas and the Fas ${ }^{\mathrm{L}}$ cells with a low expression level of Fas. The mean Fas expression in the Fas ${ }^{\mathrm{L}}$ clone (red) is shown compared to the Fas ${ }^{\mathrm{H}}$ clone (green). Cultured Fas $^{\mathrm{H}}$ and $\mathrm{Fas}^{\mathrm{L}}$ human cholangiocarcinoma cells were lysed, the levels of Fas and FasL were assayed in the lysates (20 $\mu \mathrm{g}$ protein) by Western blotting. GAPDH was performed as a control. (B) Tissue sections of paraffin-embedded cholangiocarcinoma engraftments were stained for Fas and FasL. Tumors were grown in nude mice using cultured Fas ${ }^{\mathrm{L}}$ cells for injection $(2,5)$. Immunostaining for Fas and FasL was visualized by DAB and hematoxylin. Left, negative control without Fas or FasL antibodies shows well-differentiated cholangiocarcinoma and a low background. Middle, the distribution of FasL protein is distinctly observed in tumor cells as a brown staining. Right, cells probed with Fas antibody show a low level of Fas protein is expressed in tumor engraftment as a slight brown color. (C) Total RNAs were isolated from a clone of $\mathrm{Fas}^{\mathrm{H}}$ and three clones of Fas ${ }^{\mathrm{L}}$ cells using a TRIzol reagent according to the manufacturer's protocol. One microgram of total RNA was used for first-strand cDNA synthesis. The cDNA (25 ng) was then used as templates for quantitative real-time PCR amplification of human Fas, FasL and GAPDH. The results are expressed as the mean \pm SE of the ratio of Fas transcripts (left) or FasL transcripts (right) to GAPDH transcripts in three independent experiments. ${ }^{* *} \mathrm{p}<0.01$ compared to the individual Fas ${ }^{\mathrm{L}}$ cell clones. (D) Total mRNA of $20 \mu \mathrm{g}$ from representative clones of $\mathrm{Fas}^{\mathrm{H}}$ and $\mathrm{Fas}^{\mathrm{L}}$ cells was analyzed by Northern blotting with cDNA probes for human Fas and FasL as described in Materials and methods. Fas mRNAs of $1.4 \mathrm{~kb}$ and FasL mRNAs of $1.6 \mathrm{~kb}$ (upper panel) and 28S and 18S (lower panel) are shown.

NF- $\kappa \mathrm{B}$ binding site in the Fas and FasL promoters were labeled by a kinase reaction with $\mathrm{T} 4$ polynucleotide kinase and $\left[\gamma_{-}{ }^{32} \mathrm{P}\right]-$ ATP. EMSA was performed using $2 \mathrm{ng}$ of labeled doublestrand oligonucleotides containing an NF- $\mathrm{KB}$ consensus binding motif $(10,000 \mathrm{cpm}$, Promega, Madison, WI), and $5 \mu \mathrm{g}$ of nuclear extract according to Promega's gel shift assay core system.

Plasmids, transient transfection and luciferase assay. PCRamplified fragments of the Fas promoter $(1.8 \mathrm{~kb})$ and FasL promoter $(1.7 \mathrm{~kb})$ were subcloned into KPNI and HindIII restriction sites of the luciferase reporter vector pGL3-basic (Promega). The activities of the Fas and FasL promoters in the $\mathrm{Fas}^{\mathrm{H}}$ and $\mathrm{Fas}^{\mathrm{L}}$ cells were determined by a dual-luciferase reporter assay system (Invitrogen, Carlsbad, CA). Luciferase reporter pGL3-basic vectors containing the Fas promoter or the FasL promoter were transfected into the $\mathrm{Fas}^{\mathrm{H}}$ and $\mathrm{Fas}^{\mathrm{L}}$ cells using Lipofectamine and Plus ${ }^{\mathrm{TM}}$ reagent per the manufacturer's instructions. A luciferase reporter plasmid containing RenillaLuciferase driven by an SV40 promoter (pRF-SV40) was used as an internal control for transfection efficiency. Two days after transfection, the luciferase activity in $50 \mu 1$ of cell lysate was assayed and normalized to Renilla-Luciferase activity for transfection efficiencies.

Immunohistochemical staining of Fas and FasL. Immunohistochemical staining of Fas and FasL was performed in tumor specimens produced by subcutaneous injection of the Fas $^{\mathrm{L}}$ cells into nude mice as previously described $(1,2)$. Briefly, tumor specimens were fixed in $10 \%$ formalin, embedded in paraffin, and cut into 6- $\mu \mathrm{m}$ sections (15). After dewaxing and rehydration, the slides were incubated with $0.5 \%$ hydrogen peroxide in water for 30 min to block endogenous peroxidase activity and 5\% BSA blocking buffer for 30 min to reduce nonspecific binding. Expression of Fas and FasL was determined using anti-human monoclonal antibodies (BD Biosciences, Palo Alto, CA). The secondary horseradish peroxidase (HRP)conjugated goat anti-mouse serum (Dako) was used at 1/200 for $30 \mathrm{~min}$. The color reaction was developed using 3,3'diaminobenzidine tetrahydrochloride (DAB). Negative control slides were prepared without the primary antibody but retaining all of the other steps. 


\section{Results}

Reciprocal expression of Fas and FasL proteins and transcripts in the $\mathrm{Fas}^{\mathrm{H}}$ and $\mathrm{Fas}^{L}$ cells. We generated two cell clones, $\mathrm{Fas}^{\mathrm{H}}$ and $\mathrm{Fas}^{\mathrm{L}}$ cells, based on their relative expression level of Fas (2). We first examined the expression of Fas in the Fas $^{\mathrm{L}}$ and the $\mathrm{Fas}^{\mathrm{H}}$ cells by flow cytometry. A representative result is shown in Fig. 1A. Fas expression in the Fas ${ }^{\mathrm{L}}$ cells (red line) was lower than in the $\mathrm{Fas}^{\mathrm{H}}$ cells (green line) confirming the different expression of Fas in the $\mathrm{Fas}^{\mathrm{H}}$ and $\mathrm{Fas}^{\mathrm{L}}$ cells. Using these $\mathrm{Fas}^{\mathrm{H}}$ and $\mathrm{Fas}^{\mathrm{L}}$ cells the expression of FasL was determined by Western blotting. The level of FasL protein in the $\mathrm{Fas}^{\mathrm{H}}$ cells was decreased compared to the $\mathrm{Fas}^{\mathrm{L}}$ cells (Fig. 1A).

We previously demonstrated that the Fas ${ }^{\mathrm{L}}$, but not the $\mathrm{Fas}^{\mathrm{H}}$, cells produced tumors following subcutaneous injection into nude mice (2). To confirm the reciprocal expression of Fas and FasL in engraftments, we determined the expression of Fas and FasL in formalin-fixed paraffin embedded engraftments, produced by the injection of Fas ${ }^{\mathrm{L}}$ cells into the flanks of nude mice $(1,2)$. Tumor cells were stained intensely by FasL antibody as indicated by the intense brown staining (Fig. 1B, FasL panel). As expected, Fas expression in the tumor engraftments was not detectable (Fig. 1B, Fas panel). The negative control was incubated with the secondary antibody only (Fig. 1B, control panel).

To determine whether there is a reciprocal relationship between the Fas and FasL transcripts, the relative concentrations of Fas and FasL mRNAs in the $\mathrm{Fas}^{\mathrm{H}}$ and $\mathrm{Fas}^{\mathrm{L}}$ cells were determined by quantitative real-time RT-PCR and Northern blotting assay. The ratio of Fas and FasL to GAPDH gene transcripts in the $\mathrm{Fas}^{\mathrm{H}}$ and three $\mathrm{Fas}^{\mathrm{L}}$ cell lines are shown in Fig. 1C. The Fas transcripts in the $\mathrm{Fas}^{\mathrm{H}}$ cells were approximately four times higher than in the $\mathrm{Fas}^{\mathrm{L}}$ cells, whereas the FasL transcripts in the $\mathrm{Fas}^{\mathrm{H}}$ cells were decreased compared to the Fas ${ }^{\mathrm{L}}$ cells. This reciprocal concentration of Fas and FasL mRNA transcripts was also confirmed by Northern blotting (Fig. 1D).

The function of surface FasL in the Fas ${ }^{H}$ and Fas ${ }^{L}$ cells. To assess whether the higher levels of FasL in the $\mathrm{Fas}^{\mathrm{L}}$ cells are capable of killing Fas-bearing cells, a cytotoxicity assay using ${ }^{51} \mathrm{Cr}$-labeled target cells was performed. Fig. 2 shows that the percentage of ${ }^{51} \mathrm{Cr}$ released from A20 cells induced by the Fas $^{\mathrm{L}}$ cells was markedly higher than that induced by the $\mathrm{Fas}^{\mathrm{H}}$ cells at all ratios of tumor $(\mathrm{E})$ to A20 (T) cells $(\mathrm{p}<0.001)$. The maximum ${ }^{51} \mathrm{Cr}$ release by the $\mathrm{Fas}^{\mathrm{L}}$ cells was $50-60 \%$, whereas the maximum ${ }^{51} \mathrm{Cr}$ release by the $\mathrm{Fas}^{\mathrm{H}}$ cells was 10 $20 \%$ suggesting that the increased FasL on the Fas ${ }^{\mathrm{L}}$ cells is functional in killing Fas-bearing T lymphocytes.

The function of FasL released from the Fas ${ }^{H}$ and Fas ${ }^{L}$ cells. A recent report has indicated that epithelial ovarian cancer cells secrete functional FasL in the form of microvesicles capable of inducing apoptosis of Fas-bearing immune cells (26). To determine whether $\mathrm{Fas}^{\mathrm{L}}$ and $\mathrm{Fas}^{\mathrm{H}}$ cells secrete functional FasL in microvesicles, FasL-containing microvesicles were prepared from culture supernatants collected from the $\mathrm{Fas}^{\mathrm{H}}$ and $\mathrm{Fas}^{\mathrm{L}}$ cells (26). FasL was released from these microvesicles using a lysis buffer containing $1 \%$ Triton

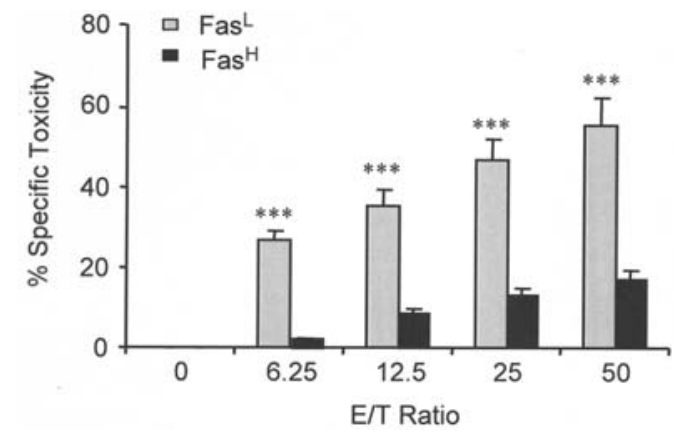

Figure 2. Function of surface FasL in the $\mathrm{Fas}^{\mathrm{H}}$ and $\mathrm{Fas}^{\mathrm{L}}$ cholangiocarcinoma cells. The $\mathrm{Fas}^{\mathrm{H}}$ and $\mathrm{Fas}^{\mathrm{L}}$ human cholangiocarcinoma cells $(\mathrm{E})$ were cocultured with ${ }^{51} \mathrm{Cr}$-labeled A20 cells (T) at the indicated ratio of E/T for $12 \mathrm{~h}$. The released radioactivity in the supernatants was measured. The Y-axis represents the percentage of specific toxicity calculated by the formula given in the Materials and methods. The $\mathrm{X}$-axis represents the ratio of $(\mathrm{E} / \mathrm{T})$. The results are shown as the mean \pm SE from three independent experiments. ${ }^{* * *} \mathrm{p}<0.001$ compared to the relative Fas $^{\mathrm{L}}$ cells in Student t-test.

$\mathrm{X}-100$ for $30 \mathrm{~min}\left(\mathrm{Fas}^{\mathrm{H}} / \mathrm{Sup}\right.$ and $\left.\mathrm{Fas}^{\mathrm{L} / \mathrm{Sup}}\right)$. PBS (Fas ${ }^{\mathrm{H}} / \mathrm{PBS}$ and $\mathrm{Fas}^{\mathrm{L}} / \mathrm{PBS}$,) was used as negative controls. Fig. 3A shows a representative experimental result. The Triton-treated supernatants from the $\mathrm{Fas}^{\mathrm{L}}$ ( $\left.\mathrm{Fas}^{\mathrm{L}} / \mathrm{Sup}\right)$, but not from the $\mathrm{Fas}^{\mathrm{H}}$ $\left(\mathrm{Fas}^{\mathrm{H}} / \mathrm{Sup}\right)$, cells profoundly activated apoptosis of Jurkat cells (right hand panels). However, the PBS-treated supernatants from both the $\mathrm{Fas}^{\mathrm{H}}\left(\mathrm{Fas}^{\mathrm{H}} / \mathrm{PBS}\right)$ and $\mathrm{Fas}^{\mathrm{L}}\left(\mathrm{Fas}^{\mathrm{L}} / \mathrm{PBS}\right)$ cells were unable to induce apoptosis of Jurkat cells. Fig. 3B shows a summary of three independent experiments. The percentage of apoptotic Jurkat cells was markedly increased when Fas antibody was added. The supernatants from the $\mathrm{Fas}^{\mathrm{L}}$, but not from the $\mathrm{Fas}^{\mathrm{H}}$, tumor cells induced apoptosis of $\mathrm{T}$ lymphocytes. The amount of apoptosis induced by supernatants from the Fas ${ }^{\mathrm{L}}$ cells was dependent on the volume of supernatant used (Fig. 3C).

To further confirm whether apoptosis of Jurkat cells is induced by FasL released from the Fas ${ }^{\mathrm{L}}$ cells, a blocking assay was performed using a neutralizing Fas antibody. Supernatants from the Fas ${ }^{\mathrm{L}}$ cells (Fas ${ }^{\mathrm{L}} / \mathrm{Sup}$ ) and Fas antibody (Fas Ab)treated cells profoundly induced apoptosis of Jurkat cells. Treatment with a neutralizing Fas antibody (nFas Ab) markedly inhibited this apoptosis ( $<<0.01$, Fig. 3D). Apoptosis induced by a Fas antibody was reduced from $84 \%$ to $23 \%$ by a neutralizing Fas antibody. Similarly, a neutralizing Fas antibody also reduced apoptosis by the supernatants from the Fas ${ }^{\mathrm{L}}$ cells from $73 \%$ to $37 \%$.

Promoter activity of the Fas and FasL in the Fas ${ }^{H}$ and Fas ${ }^{L}$ cells. To begin elucidating the mechanism(s) for the inverse expression of Fas and FasL in the $\mathrm{Fas}^{\mathrm{L}}$ and $\mathrm{Fas}^{\mathrm{H}}$ cells, the activities of both the Fas and the FasL promoters were determined. We constructed plasmids containing a luciferase reporter gene regulated by the Fas promoter (FaspromoterLuc) or FasL promoter (FasLpromoter-Luc). These plasmids were transfected into the $\mathrm{Fas}^{\mathrm{L}}$ and $\mathrm{Fas}^{\mathrm{H}}$ cells and luciferase activities were determined at $48 \mathrm{~h}$ post-transfection.

As shown in Fig. 4, both Fas and FasL promoters contain $\mathrm{NF}-\kappa \mathrm{B}$ binding motifs. Luciferase activity driven by the Fas promoter in the $\mathrm{Fas}^{\mathrm{H}}$ cells was significantly greater than in the Fas $^{\mathrm{L}}$ cells $(\mathrm{p}<0.001)$ indicating a strong Fas promoter 
A
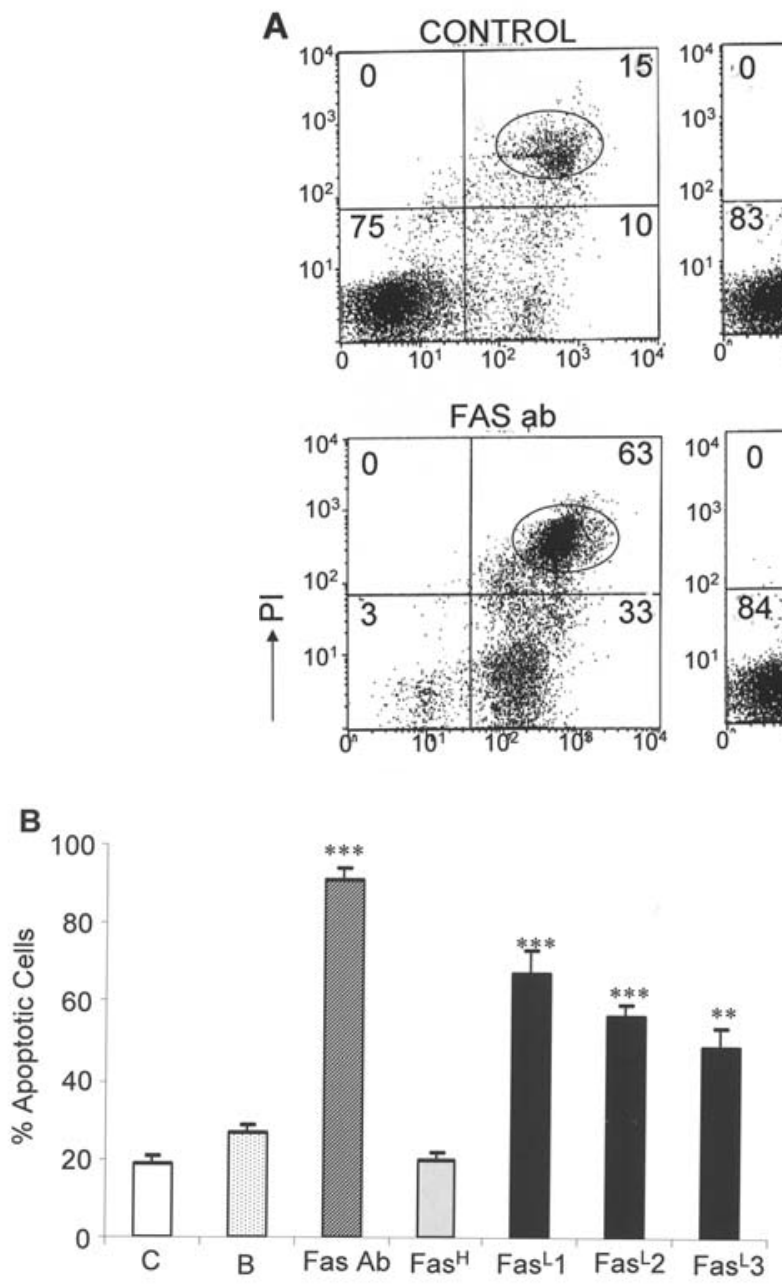

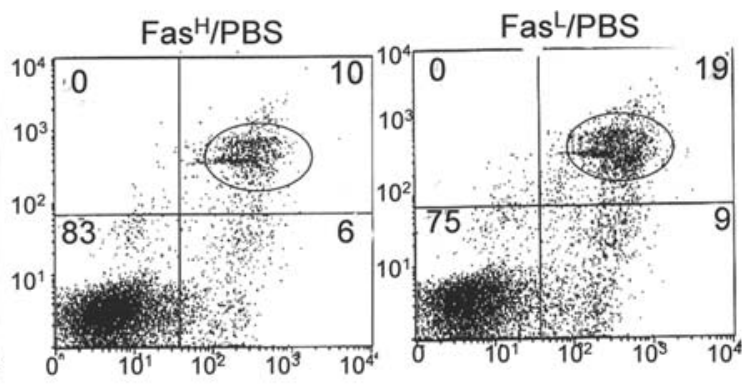

$\mathrm{Fas}^{\mathrm{H}} / \mathrm{Sup}$

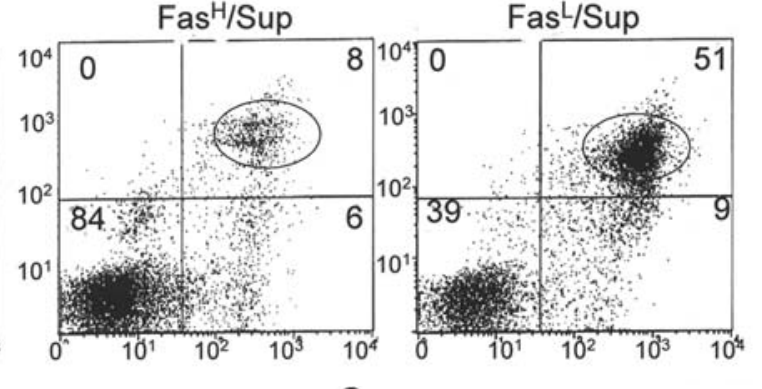

C

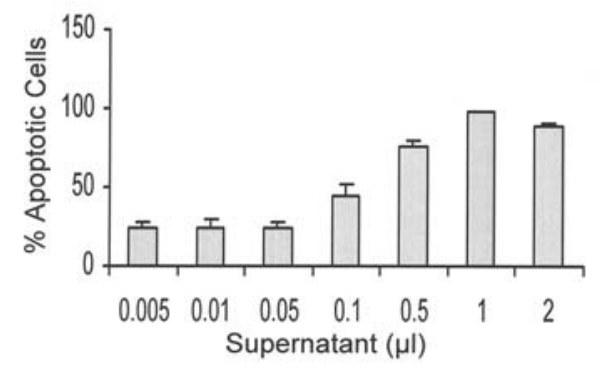

D

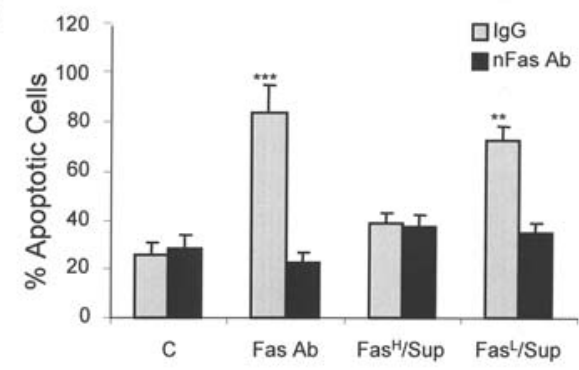

Figure 3. FasL secreted from the Fas ${ }^{\mathrm{L}}$ tumor cells is functional. (A) Microvesicles were prepared from the culture supernatants of the Fas ${ }^{\mathrm{H}}$ and Fas ${ }^{\mathrm{L}}$ cells and treated with a lysis buffer containing $1 \%$ Triton X-100 $\left(\mathrm{Fas}^{\mathrm{H}} / \mathrm{Sup}\right.$ or Fas $\left.{ }^{\mathrm{L}} / \mathrm{Sup}\right)$ or PBS (Fas $/ \mathrm{HBS}$ or Fas $\left./ \mathrm{PBS}\right)$ overnight. Jurkat cells $\left(5 \times 10^{5}\right)$ were incubated with medium as a negative control, $50 \mathrm{ng} / \mathrm{ml}$ Fas antibody as a positive control (Fas ab), or $0.5 \mu 1$ microvesicle supernatants or PBS alone. The percentage of apoptotic cells was determined using an Annexin V assay. The figure shows a representative flow cytometric result. The numbers in the quadrants represent the percentage of cells. Apoptotic cells are in the lower and upper right quadrants. (B) Jurkat cells were incubated with medium as a control (C), $1 \%$ Triton X100 lysis buffer (B), $50 \mathrm{ng} / \mathrm{ml}$ Fas antibody as a positive control (Fas Ab), and 1\% Triton X-100-treated fractions isolated from the culture supernatants of $\mathrm{Fas}^{\mathrm{H}}\left(\mathrm{Fas}^{\mathrm{H} / \mathrm{Sup}}\right)$ and three representative $\mathrm{Fas}^{\mathrm{L}}$ cholangiocarcinoma cell clones ( $\mathrm{Fas}^{\mathrm{L}} / \mathrm{Sup} 1$, Fas ${ }^{\mathrm{L}} / \mathrm{Sup} 2$, Fas $\left.{ }^{\mathrm{L}} / \mathrm{Sup} 3\right)$ were incubated overnight and then apoptosis of Jurkat cells was determined by an Annexin V assay. The figure shows the mean $\pm \mathrm{SE}$ of percentage of cell death in three individual experiments. ${ }^{* *} \mathrm{p}<0.01$ and ${ }^{* * *} \mathrm{p}<0.001$ versus the $\mathrm{Fas}^{\mathrm{H}}$ cells in Student t-test. (C) Jurkat cells were incubated with the indicated volumes of supernatant prepared from the Fas ${ }^{\mathrm{L}}$ cells overnight. Apoptotic cells were detected by Annexin V. The results are shown as the mean \pm SE from three independent experiments. (D) Jurkat cells were preincubated with $2 \mathrm{ng} / \mathrm{ml}$ neutralizing Fas antibody (nFas Ab, black column) or mouse IgG (gray column) for $1 \mathrm{~h}$ and then incubated with medium (C), $50 \mathrm{ng} / \mathrm{ml}$ activating Fas $\mathrm{Ab}$ (Fas Ab), and supernatant fractions isolated from the cultured supernatants of $\mathrm{Fas}^{\mathrm{H}}$ (Fas ${ }^{\mathrm{H}} / \mathrm{Sup}$ ) and $\mathrm{Fas}^{\mathrm{L}}$ (Fas ${ }^{\mathrm{L}} / \mathrm{Sup}$ ) cholangiocarcinoma cells overnight. Cell death was determined using an Annexin V assay. The results are shown as the mean \pm SE from three independent experiments. ${ }^{* *} \mathrm{p}<0.01$ and ${ }^{* * *} \mathrm{p}<0.001$ compared with the treatment of neutralizing Fas antibody in Student $\mathrm{t}$-test.

activity in the $\mathrm{Fas}^{\mathrm{H}}$ cells compared to the $\mathrm{Fas}^{\mathrm{L}}$ cells. Luciferase activity driven by the FasL promoter in the $\mathrm{Fas}^{\mathrm{H}}$ cells is significantly lower than in the Fas ${ }^{\mathrm{L}}$ cells $(\mathrm{p}<0.001)$ showing a low FasL promoter activity in the $\mathrm{Fas}^{\mathrm{H}}$ cells compared to the $\mathrm{Fas}^{\mathrm{L}}$ cells. These results indicate that an inverse expression of Fas and FasL in the Fas ${ }^{\mathrm{L}}$ and $\mathrm{Fas}^{\mathrm{H}}$ cells is most likely due to reciprocal promoter activities of the Fas and FasL genes.
Reciprocal promoter activity of the Fas and FasL genes is regulated by $N F-\kappa B$. To determine the mechanism whereby the activities of the Fas and FasL promoters are inversely regulated, we first determined the binding of nuclear extracts from the $\mathrm{Fas}^{\mathrm{L}}$ and $\mathrm{Fas}^{\mathrm{H}}$ cells to NF- $\mathrm{kB}$ oligonucleotides by EMSA analysis. As demonstrated in Fig. 5A, the $\mathrm{Fas}^{\mathrm{L}}$ cells had higher NF- $\mathrm{kB}$ binding capacity compared to the $\mathrm{Fas}^{\mathrm{H}}$ cells. The regulatory activity of the NF- $\mathrm{KB}$ transcription factor 

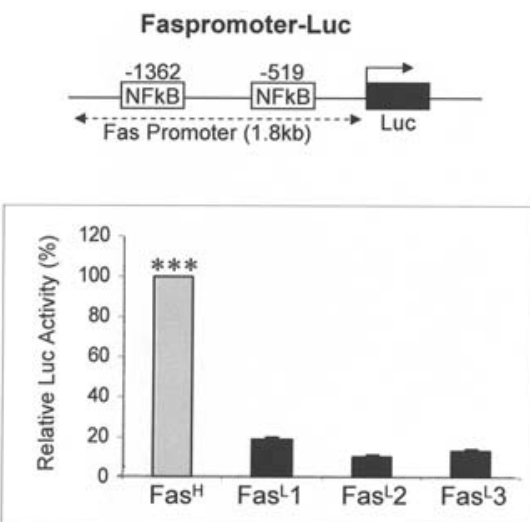
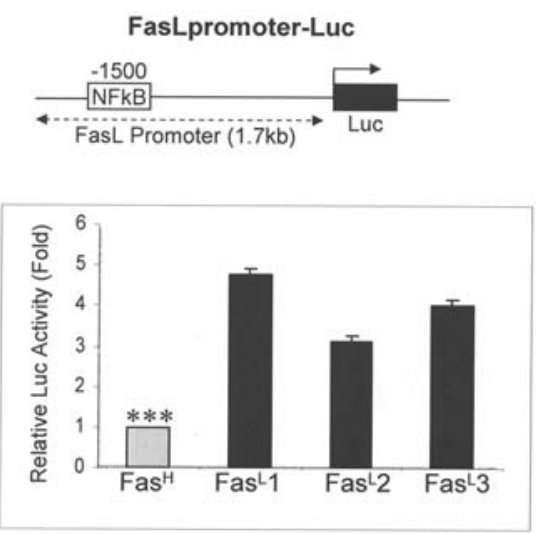

Figure 4. Schematic illustration of Faspromoter-Luc and FasLpromoter-Luc and their activities in the Fas ${ }^{\mathrm{L}}$ and Fas ${ }^{\mathrm{H}}$ cells. Two luciferase-expressing plasmids driven by the Fas promoter (1.8 kb, Faspromoter-Luc) or the FasL promoter (1.7kb, FasLpromoter-Luc) and the location of NF- $\mathrm{B}$ binding motifs in the promoters are illustrated. The $\mathrm{Fas}^{\mathrm{H}}$ and $\mathrm{Fas}^{\mathrm{L}}$ cells were transiently transfected with these plasmids, respectively. At $48 \mathrm{~h}$ after transfection, luciferase activity in $50 \mu 1$ cell lysate was measured as per manufacturer's protocol. The results are shown from three independent experiments and presented as the mean \pm SE. ${ }^{* * *} \mathrm{p}<0.001$ versus the other cell clones in Student t-test.
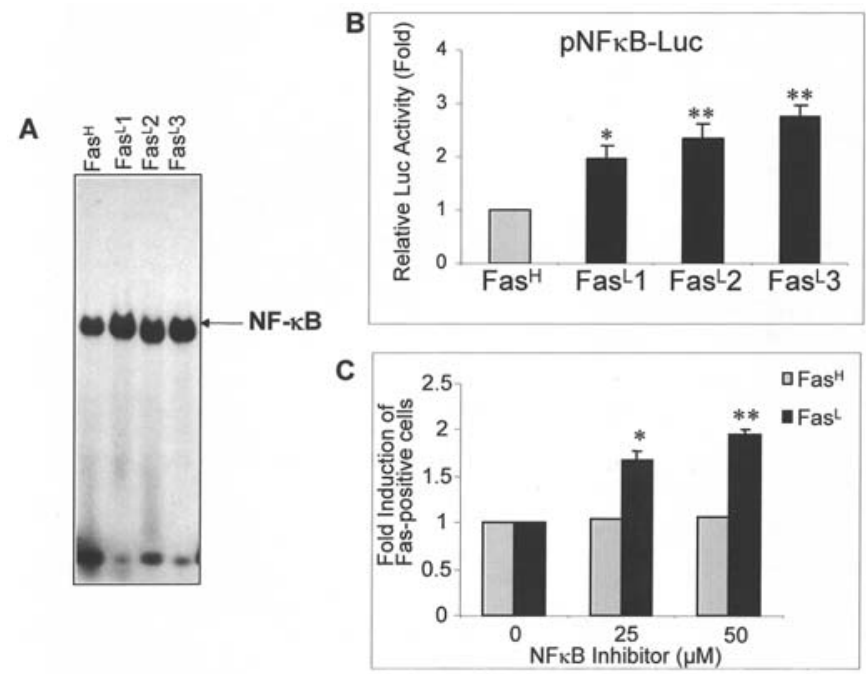

Figure 5. The intracellular NF- $\mathrm{BB}$ transcription factor is increased in the Fas $^{\mathrm{L}}$ cells. Nuclear extracts were prepared from the $\mathrm{Fas}^{\mathrm{L}}$ and $\mathrm{Fas}^{\mathrm{H}}$ cells. (A) EMSA was performed using $5 \mu \mathrm{g}$ nuclear protein and ${ }^{32} \mathrm{P}$-labeled NF- $\mathrm{KB}$ oligonucleotides. The DNA-protein complex was resolved on $4.5 \%$ native polyacrylamide gels and then dried gels were exposed to X-films. The signal of DNA-protein complex in the Fas ${ }^{\mathrm{L}}$ and $\mathrm{Fas}^{\mathrm{H}}$ cells is indicated. (B) Luciferase assay for the activity of transcription factors. $\mathrm{Fas}^{\mathrm{H}}$ and $\mathrm{Fas}^{\mathrm{L}}$ tumor cells were transiently transfected with luciferase expression plasmids, in which the

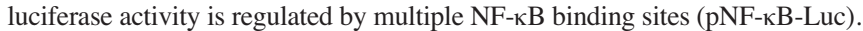
A plasmid lacking the transcription factor-binding site (pRF-Luc) was used as a negative control. Cells were harvested $48 \mathrm{~h}$ after transfection, lysates were prepared, and luciferase activity was quantified in a Packard luminometer. The results shown here are the mean \pm SE from three independent experiments. ${ }^{* *} \mathrm{p}<0.01$ and ${ }^{*} \mathrm{p}<0.05$ compared to the $\mathrm{Fas}^{\mathrm{H}}$ cell clone in Student t-test. (C) $\mathrm{Fas}^{\mathrm{H}}$ and $\mathrm{Fas}^{\mathrm{L}}$ cells were cultured with the indicated concentrations of NF-кB inhibitor, ADPC, for $48 \mathrm{~h}$ and then stained for Fas using a PE-conjugated mouse anti-Fas antibody. The Y-axis represents fold induction of Fas-positive cells, calculated by dividing Fas-positive cell number in the presence of NF- $\mathrm{\kappa B}$ inhibitor by Fas-positive cell number in the absence of the inhibitor. The data are presented as the mean $\pm \mathrm{SE}$ of three independent experiments. ${ }^{*} \mathrm{p}<0.05$ and ${ }^{* *} \mathrm{p}<0.01$ compared to the relative $\mathrm{Fas}^{\mathrm{H}}$ cell clone in Student t-test.

in the $\mathrm{Fas}^{\mathrm{L}}$ and $\mathrm{Fas}^{\mathrm{H}}$ cells was then determined using a reporter construct for NF- $\mathrm{KB}$ (pNF- $\mathrm{kB}-\mathrm{Luc}$ ) following transient transfection for $48 \mathrm{~h}$ (Stratagene). The control construct, pRF-Luc was concurrently transfected to normalize for transfection efficiency. Fig. 5B shows that luciferase activity in the FasL cells was markedly increased compared to the $\mathrm{Fas}^{\mathrm{H}}$ cells.

To further assess the role of the NF- $\kappa \mathrm{B}$ transcription factor in reciprocally regulating the expression of Fas and FasL we examined the effect of the NF- $\mathrm{kB}$ inhibitor, Ammonium Pyrrolidinedithiocarbamate (APDC, Tocris, Elliscille, MO) on Fas expression $(28,29)$. The percentages of Fas-positive cells prior to and after APDC treatment were detected by flow cytometry. The data are presented as the fold induction of Fas-positive cells in the presence of APDC compared to Faspositive cells in the absence of APDC (Fig. 5C). Without APDC treatment, the number of Fas-positive cells was not changed before and after treatment in the $\mathrm{Fas}^{\mathrm{L}}$ and $\mathrm{Fas}^{\mathrm{H}}$ cells. APDC increased the number of Fas-positive cells in the Fas ${ }^{\mathrm{L}}$ cells, but not in the Fas ${ }^{\mathrm{H}}$ cells, by two-fold $(\mathrm{p}<0.05)$, suggesting that the inhibition of NF- $\mathrm{\kappa B}$ stimulates Fas expression in the $\mathrm{Fas}^{\mathrm{L}}$ cells increasing the numbers of Fas-positive cells.

\section{Discussion}

In this study we determined FasL expression in the $\mathrm{Fas}^{\mathrm{H}}$ and Fas $^{\mathrm{L}}$ cells and demonstrated that the level of FasL expression in human cholangiocarcinoma cells is inversely related to that of Fas. A wide variety of malignancies, such as pancreas, liver, breast, and esophagus, have been reported to express decreased Fas as well as high FasL (30-32), whereas normal tissues from these organs do not express FasL. Strand et al analyzed the expression of both Fas and FasL in 22 hepatocellular carcinomas and suggested that tumor cells can evade immune attack by down-regulation of Fas and induce apoptosis of Fas-bearing lymphocytes through the elevated expression of FasL. The binding of FasL on tumor cells to the Fas molecule on lymphocytes triggered the lymphocytes to undergo apoptosis (33). Our results with cholangiocarcinoma confirm this inverse relationship of Fas and FasL expression in a cellular model and initiate the elucidation of the underlying molecular mechanisms.

The role of a deficiency of Fas expression or function in tumorigenesis has been extensively studied. It has been 
reported that the potential for metastasis of osteosarcoma is inversely correlated with Fas expression (7). In cholangiocarcinoma, down-regulation of Fas significantly correlated with histological de-differentiation, vascular invasion, and the size of the tumor (22). However, dysregulation of Fas expression alone was reported to be insufficient to promote tumor progression, because blocking Fas expression in the Fas-expressing cells did not reduce tumor progression (8), implying that other genes may also contribute. Aberrant FasL expression in the $\mathrm{Fas}^{\mathrm{L}}$ cells may contribute to its tumorigenic capacity.

The role of FasL expression in tumorigenesis remains controversial. For example, FasL-expressing carcinomas had significantly higher potential of lymph node and distant metastases than carcinomas that did not express FasL, supporting the hypothesis that aberrant FasL expression enhances tumor growth and metastasis (34). In contrast to this hypothesis, suppressing FasL expression in melanoma cells enhanced lung metastasis (35). In addition, other controversies concern the specificity of the reagents used for detection of FasL (antibodies, PCR assay, primers), the presence or absence of tumor-specific $\mathrm{T}$ lymphocytes infiltrating cancer lesions and whether or not tumors regress following delivery of FasLexpressing $\mathrm{T}$ cells into mice $(19,36)$. Using heterogeneous cell lines may also cause varying results. The use of homogenous cloned cells in our system avoids these controversial factors providing an opportunity to simultaneously determine the roles of Fas and FasL in tumorigenesis. Our results indicate that increased FasL, either on the membrane of or released from the Fas ${ }^{\mathrm{L}}$ cells, is capable of inducing apoptosis of Jurkat lymphocytes (Fig. 3) suggesting the function of FasL on tumor cells in protecting from immune attack by the host. It has been reported that the prognosis of patients with malignant tumors is dependent on the FasL expression of their tumors and the concomitant presence of apoptotic $\mathrm{T}$ cells in tumor lesions. Thus, the Fas ${ }^{\mathrm{L}}$ cells not only have an acquired defensive mechanism (Fas resistance), but also provide an offensive mechanism (counterattack) through expressing FasL (37).

In tumors, FasL has been demonstrated to have two forms: surface and soluble. The surface FasL is responsible for transduction of the Fas apoptotic signal after cell-cell contact (38). The soluble FasL (sFasL) released from tumor cells by a proteolytic metalloproteinase is unable to transduce the apoptotic death signal and, therefore, presumably suppresses Fas-mediated apoptosis as a decoy receptor for Fas (39). Abrahams et al reported that epithelial ovarian cancer cells secrete functional FasL via microvesicles (26). We detected this microvesicle-associated active FasL in the $\mathrm{Fas}^{\mathrm{L}}$ cholangiocarcinoma cells. The Fas ${ }^{\mathrm{L}}$ cells, but not the $\mathrm{Fas}^{\mathrm{H}}$ cells, secrete functional FasL in microvesicles capable of activating Fasmediated apoptosis of Jurkat cells (Fig. 3). Blockage of apoptosis by a neutralizing Fas antibody indicates that the Fas/FasL interaction is responsible for the apoptosis of the Jurkat cells induced by secreted sFasL. Thus, the secreted form of microvesicle-associated FasL in the Fas $^{\mathrm{L}}$ cells is a potential mechanism for counterattack and immune surveillance.

Simultaneous analysis of both Fas and FasL expression in the $\mathrm{Fas}^{\mathrm{H}}$ and $\mathrm{Fas}^{\mathrm{L}}$ cells provides insight into the mechanisms of reciprocal co-expression of Fas and FasL. The alteration in the Fas promoter region might result in the lack of Fas expression
(40). However, we analyzed the partial DNA sequences of the Fas and FasL promoter regions in the $\mathrm{Fas}^{\mathrm{H}}$ and $\mathrm{Fas}^{\mathrm{L}}$ cholangiocarcinoma cells. No mutations or other alterations in either the Fas or FasL promoter region were identified (data not shown). Su et al studied Jurkat T lymphocytes that were transfected with an hFasLpro/GFP plasmid, in which the GFP gene is controlled by FasL promoter. They found that GFPpositive cells expressed low Fas, whereas GFP-negative cells expressed higher levels of Fas protein, indicating an inverse relationship between Fas promoter and FasL promoter activity in tumors (41). Our results confirmed inverse activities of Fas and FasL promoters in the $\mathrm{Fas}^{\mathrm{H}}$ and $\mathrm{Fas}^{\mathrm{L}}$ cells (Fig. 4). This suggests that some common transcription factors may participate in the reciprocal regulation of Fas and FasL expression.

The transcriptional machinery regulating the expression of Fas and FasL is not yet fully known. Several transcription factors have been identified that regulate Fas and FasL expression. Watabe et al reported that transcription factor, $\mathrm{NF}-\kappa \mathrm{B}$, down-regulates Fas activation and inhibits Fasmediated apoptosis (42), whereas Lu et al reported that NF-кB up-regulates FasL expression and activates FasL-mediated apoptosis (43). Several studies identified the location of NF-кB binding motifs in the Fas $(44,45)$ and FasL promoters $(46,47)$ (Fig. 4). In this study, we simultaneously analyzed the effects of NF- $\mathrm{KB}$ on Fas and FasL and found that the Fas ${ }^{\mathrm{L}}$ cells have higher activity of NF- $\mathrm{KB}$ compared to the $\mathrm{Fas}^{\mathrm{H}}$ cells (Fig. 5). These observations confirm that NF- $\mathrm{KB}$ down-regulates Fas and up-regulates FasL, simultaneously. Furthermore, inhibiting this elevated NF- $\mathrm{KB}$ activity in the Fas ${ }^{\mathrm{L}}$ cells by APDC, an NF-кB inhibitor, significantly increased Fas and decreased FasL expression. Lu et al demonstrated that FasL-induced apoptosis was increased and TNF- $\alpha$ expression decreased by a specific $\mathrm{NF}-\kappa \mathrm{B}$ inhibitor or dominant expression of IкB subunit (43).

In conclusion, human cholangiocarcinoma cells reciprocally express functional Fas and FasL, which may be caused by the inverse activity of the Fas and FasL promoter regulated by NF- $\mathrm{BB}$. Reciprocal expression of Fas and FasL in human cholangiocarcinoma may contribute to the survival of tumor cells, the failure of immune surveillance, and growth and metastasis of tumors. Regulating a single mechanism responsible for this reciprocal expression may provide opportunities for new therapies.

\section{Acknowledgments}

We thank Marsha Moore and Traci Oden for help in the preparation of the manuscript. We also thank Margaret A. McKenna for her critical reading of the manuscript. This study was supported by a Merit Award from the Veterans Administration (JMM).

\section{References}

1. Pickens A, Pan G, McDonald JM, and Vickers SM: Fas expression prevents cholangiocarcinoma tumor growth. J Gastrointest Surg 3: 374-382, 1999.

2. Pan G, Vickers SM, Pickens A, et al: Apoptosis and tumorigenesis in human cholangiocarcinoma cells. Involvement of Fas/APO-1 (CD95) and calmodulin. Am J Pathol 155: 193-203, 1999. 
3. Ahn EY, Pan G, Oh JH, et al: The combination of calmodulin antagonists and interferon-gamma induces apoptosis through caspase-dependent and -independent pathways in cholangiocarcinoma cells. Am J Pathol 163: 2053-2063, 2003.

4. Vickers SM, Jhala NC, Ahn EY, et al: Tamoxifen (TMX)/Fas induced growth inhibition of human cholangiocarcinoma (HCC) by gamma interferon (IFN-gamma). Ann Surg 235: 872-878, 2002 .

5. Ahn EY, Pan G, Vickers SM and McDonald JM: IFN-gamma upregulates apoptosis-related molecules and enhances Fasmediated apoptosis in human cholangiocarcinoma. Int J Cancer 100: 445-451, 2002.

6. Owen-Schaub LB, van Golen KL, Hill L and Price JE: Fas and Fas ligand interactions suppress melanoma lung metastasis. J Exp Med 188: 1717-1723, 1998.

7. Worth LL, Lafleur EA, Jia SF and Kleinerman ES: Fas expression inversely correlates with metastatic potential in osteosarcoma cells. Oncol Rep 9: 823-827, 2002.

8. Liu K and Abrams SI: Alterations in Fas expression are characteristic of, but not solely responsible for, enhanced metastatic competence. J Immunol 170: 5973-5980, 2003.

9. Rivoltini L, Carrabba M, Huber V, et al: Immunity to cancer: attack and escape in T lymphocyte-tumor cell interaction. Immunol Rev 188: 97-113, 2002.

10. Costello RT, Gastaut JA and Olive D: Mechanisms of tumor escape from immunologic response. Rev Med Interne 20: 579-588, 1999.

11. Saas P, Walker PR, Hahne M, et al: Fas ligand expression by astrocytoma in vivo: maintaining immune privilege in the brain? J Clin Invest 99: 1173-1178, 1997.

12. Houston A, Waldron-Lynch FD, Bennett MW, et al: Fas ligand expressed in colon cancer is not associated with increased apoptosis of tumor cells in vivo. Int J Cancer 107: 209-214, 2003.

13. Eberle J, Fecker LF, Hossini AM, et al: CD95/Fas signaling in human melanoma cells: conditional expression of CD95L/FasL overcomes the intrinsic apoptosis resistance of malignant melanoma and inhibits growth and progression of human melanoma xenotransplants. Oncogene 22: 9131-9141, 2003.

14. Igney FH, Behrens CK and Krammer PH: The influence of CD95L expression on tumor rejection in mice. Eur J Immunol 33: 2811-2821, 2003.

15. Mhashilkar AM, Schrock RD, Hindi M, et al: Melanoma differentiation associated gene-7 (mda-7): a novel anti-tumor gene for cancer gene therapy. Mol Med 7: 271-282, 2001.

16. Tada Y, J OW, Takiguchi Y, et al: Cutting edge: a novel role for Fas ligand in facilitating antigen acquisition by dendritic cells. J Immunol 169: 2241-2245, 2002.

17. Hahne M, Rimoldi D, Schroter M, et al: Melanoma cell expression of Fas(Apo-1/CD95) ligand: implications for tumor immune escape. Science 274: 1363-1366, 1996.

18. Green DR, Droin N and Pinkoski M: Activation-induced cell death in T cells. Immunol Rev 193: 70-81, 2003.

19. Restifo NP: Not so Fas: Re-evaluating the mechanisms of immune privilege and tumor escape. Nat Med 6: 493-495, 2000.

20. Kang SM, Schneider DB, Lin Z, et al: Fas ligand expression in islets of Langerhans does not confer immune privilege and instead targets them for rapid destruction. Nat Med 3: 738-743, 1997.

21. Saposnik G, Maurino J and Bueri J: Movements in brain death. Eur J Neurol 8: 209-213, 2001.

22. Shimonishi T, Isse K, Shibata F, et al: Up-regulation of fas ligand at early stages and down-regulation of Fas at progressed stages of intrahepatic cholangiocarcinoma reflect evasion from immune surveillance. Hepatology 32: 761-769, 2000.

23. Ito Y, Takeda T, Sasaki Y, et al: Expression of Fas and Fas ligand reflects the biological characteristics but not the status of apoptosis of intrahepatic cholangiocellular carcinoma. Int J Mol Med 6: 581-586, 2000

24. Zayzafoon M, Abdulkadir SA and McDonald JM: Notch signaling and ERK activation are important for the osteomimetic properties of prostate cancer bone metastatic cell lines. J Biol Chem 279: 3662-3670, 2004.

25. Hohlbaum AM, Moe S and Marshak-Rothstein A: Opposing effects of transmembrane and soluble Fas ligand expression on inflammation and tumor cell survival. J Exp Med 191: 1209-1220, 2000 .
26. Abrahams VM, Straszewski SL, Kamsteeg M, et al: Epithelial ovarian cancer cells secrete functional Fas ligand. Cancer Res 63: 5573-5581, 2003.

27. Schreiber E, Matthias P, Muller MM and Schaffner W: Rapid detection of octamer binding proteins with 'mini-extracts', prepared from a small number of cells. Nucleic Acids Res 17: $6419,1989$.

28. Tsai JC, Jain M, Hsieh CM, et al: Induction of apoptosis by pyrrolidinedithiocarbamate and $\mathrm{N}$-acetylcysteine in vascular smooth muscle cells. J Biol Chem 271: 3667-3670, 1996.

29. Pan Z, Kravchenko VV and Ye RD: Platelet-activating factor stimulates transcription of the heparin-binding epidermal growth factor-like growth factor in monocytes. Correlation with an increased kappa B binding activity. J Biol Chem 270: 7787-7790, 1995

30. Rajashekhar G, Loganath A, Roy AC and Mongelli JM: Coexpression of Fas (APO-1, CD95)/Fas ligand by BeWo and NJG choriocarcinoma cell lines. Gynecol Oncol 91: 101-111, 2003.

31. Gastman BR, Atarshi Y, Reichert TE, et al: Fas ligand is expressed on human squamous cell carcinomas of the head and neck, and it promotes apoptosis of T lymphocytes. Cancer Res 59: 5356-5364, 1999.

32. Shibakita M, Tachibana M, Dhar DK, et al: Prognostic significance of Fas and Fas ligand expressions in human esophageal cancer. Clin Cancer Res 5: 2464-2469, 1999.

33. Strand S, Hofmann WJ, Hug H, et al: Lymphocyte apoptosis induced by CD95 (APO-1/Fas) ligand-expressing tumor cells a mechanism of immune evasion? Nat Med 2: 1361-1366, 1996.

34. Nozoe T, Yasuda M, Honda M, et al: Fas ligand expression is correlated with metastasis in colorectal carcinoma. Oncology 65: 83-88, 2003.

35. Chen YL, Wang JY, Chen SH and Yang BC: Granulocytes mediates the Fas-L-associated apoptosis during lung metastasis of melanoma that determines the metastatic behaviour. Br J Cancer 87: 359-365, 2002.

36. Restifo NP: Countering the 'counterattack' hypothesis. Nat Med 7: 259, 2001

37. O'Connell J, Bennett MW, O'Sullivan GC, et al: Fas counterattack - the best form of tumor defense? Nat Med 5: 267-268, 1999.

38. Nagata $S$ and Golstein P: The Fas death factor. Science 267: 1449-1456, 1995

39. Alderson MR, Tough TW, Davis-Smith T, et al: Fas ligand mediates activation-induced cell death in human $\mathrm{T}$ lymphocytes. J Exp Med 181: 71-77, 1995

40. Sibley K, Rollinson S, Allan JM, et al: Functional FAS promoter polymorphisms are associated with increased risk of acute myeloid leukemia. Cancer Res 63: 4327-4330, 2003.

41. Su X, Cheng J, Liu W, et al: Autocrine and paracrine apoptosis are mediated by differential regulation of Fas ligand activity in two distinct Jurkat T cell populations. J Immunol 160: 5288-5293, 1998.

42. Watabe M, Hishikawa K, Takayanagi A, et al: Caffeic acid phenethyl ester induces apoptosis by inhibition of NFkappaB and activation of Fas in human breast cancer MCF-7 cells. J Biol Chem 279: 6017-6026, 2004.

43. Lu B, Wang L, Medan D, et al: Regulation of Fas (CD95)induced apoptosis by nuclear factor-kappaB and tumor necrosis factor-alpha in macrophages. Am J Physiol Cell Physiol 283: C831-C838, 2002.

44. Zheng Y, Ouaaz F, Bruzzo P, et al: NF-kappa B RelA (p65) is essential for TNF-alpha-induced fas expression but dispensable for both TCR-induced expression and activation-induced cell death. J Immunol 166: 4949-4957, 2001.

45. Darville MI and Eizirik DL: Cytokine induction of Fas gene expression in insulin-producing cells requires the transcription factors NF-kappaB and C/EBP. Diabetes 50: 1741-1748, 2001.

46. Kasibhatla S, Brunner T, Genestier L, et al: DNA damaging agents induce expression of Fas ligand and subsequent apoptosis in T lymphocytes via the activation of NF-kappa B and AP-1. Mol Cell 1: 543-551, 1998.

47. Matsui K, Fine A, Zhu B, et al: Identification of two NF-kappa $\mathrm{B}$ sites in mouse CD95 ligand (Fas ligand) promoter: functional analysis in T cell hybridoma. J Immunol 161: 3469-3473, 1998 . 